\title{
Educação e Imigração: a importância do ensino da Sociologia para imigrantes
}

Recebido: 21-01-2019

Aprovado: 10-04-2019

Tânia Tonhati ${ }^{1}$

\section{Introdução}

Nas últimas duas décadas, o Brasil voltou a ser destaque como país receptor de imigrantes. Nesse período sobressaiu-se o volume e também a diversidade dos fluxos migratórios para o país. Destacam-se os coletivos de países como Haiti, que teve grande chegada de imigrantes de 2010 até meados de 2016, e mais recentemente os imigrantes do país vizinho à Venezuela. Uma série de estudos foi realizada tendo esses grupos de imigrantes como foco. Por exemplo, Cavalcanti, et al. (2016) e Handerson (2015) vão explicar a migração haitiana para o Brasil e também os nichos de inserção laboral desses. Há também estudos como de Tonhati (2016) e Silva (2015), que discutiram as formas de entradas desses migrantes pelas fronteiras do Norte do país. Já Simões (2017) elabora um perfil dos migrantes venezuelanos no país.

Tais pesquisas, assim como outras, têm observado que esses coletivos estão geralmente em situação de vulnerabilidade social e possuem uma série de dificuldades de integração sociocultural na sociedade brasileira. Embora já se tenha estudos sobre esses coletivos, muito pouco se sabe até o presente momento sobre as formas de integração sociocultural das crianças e adolescentes imigrantes desses novos fluxos no Brasil. Os

\footnotetext{
${ }^{1}$ Doutora pela Universidade de Londres (Goldsmiths), no Departamento de Sociologia, onde realizou pesquisa sobre migrações internacionais, política e gestão migratória, mulheres brasileiras e o campo social transnacional desenvolvido pelos migrantes brasileiros entre o Reino Unido e o Brasil, com olhar específico para família transnacional. Foi coordenadora assistente e pesquisadora na Universidade de Oxford, no projeto de pesquisa THEMIS (Theorizing the Evolution Migration System - Oxford University). Desenvolveu e coordenou pesquisas sobre a migração brasileira no Reino Unido através do Grupo de Estudos sobre os Brasileiros no Reino Unido (GEB), o que gerou publicações de relatórios e de artigos em periódicos indexados. Ademais, foi consultora da Organização Internacional das Migrações (OIM) e Organização Pan Americana da Saúde (OPAS/OMS) desenvolvendo e coordenando pesquisa sobre os novos fluxos migratórios para o Brasil e políticas públicas. Temas de interesse de pesquisa: migrações internacionais, políticas públicas, família. Brasil. Email: taniatonhati@gmail.com
} 
números demonstram que crianças e adolescentes imigrantes são menos de $10 \%$ da migração regular, no entanto, essa é uma população que demanda atenção especial para se integrarem, já que utilizam de vários espaços como escolas, postos de saúde e demais locais de sociabilidade, que são em sua maioria pensada exclusivamente para nacionais (Oliveira, 2018). Nesse sentido, é imprescindível um olhar mais aprofundado para as necessidades das crianças e adolescentes imigrantes com relação à sua inserção e participação na educação formal no Brasil.

Desse modo, esse texto objetiva ser um chamado para pesquisas e análises de como a disciplina de Sociologia pode contribuir para a integração sociocultural das crianças e adolescentes imigrantes no Brasil e, em que medida essa pode vir a contribuir para o combate à xenofobia, violência e discriminação voltada para esses coletivos.

\section{O Ensino da Sociologia na Educação no Brasil}

O ensino da Sociologia na escola no Brasil tem um contexto histórico intermitente de avanços e regressos, onde sua legitimidade e consolidação dentro da base curricular foram cambiantes ao longo de todo século XX e XXI. De modo geral, como argumenta Fiorelli (2010) as Ciências Sociais entraram nos currículos da antiga escola secundária brasileira através da Sociologia e também via História, Geografia, Economia, Educação Moral e Cívica e Estudos Sociais. No entanto, de forma explícita, como disciplina autônoma em relação às outras disciplinas, considera-se que a inclusão da Sociologia iniciou-se no período de 1925 a 1942. Nessa fase, é possível identificar evidências da institucionalização e sistematização da disciplina no ensino básico e posteriormente superior.

Antes de 1933, a autora Fiorelli (2010) argumenta que não foi possível encontrar no Brasil espaços oficiais de formação e produção acadêmica em Sociologia. Esse período seria considerado como uma fase "pré-acadêmica", em que se praticavam as Ciências Sociais de forma autodidata e no ensino nos cursos de preparação para o exercício do magistério como nas Escolas Normais e nas então denominadas Escolas Secundárias. Nessa fase os materiais didáticos e pedagógicos eram em sua maioria traduzidos do francês e editados por professores de áreas do conhecimento afins as Ciências Sociais.

Quando analisado historicamente o processo de incorporação da Sociologia nas escolas no Brasil nota-se que esse está entremeado no modo como o Brasil constituiu seu 
sistema educacional, científico e, ainda, com os contextos políticos de cada época. As relações entre esses campos foram elementos importantes na instauração, continuação, legitimação e consolidação do ensino da Sociologia no interior dos currículos da educação básica. Constantes mudanças de nomenclaturas e agrupamentos de disciplinas criaram um imbróglio sobre os desenvolvimentos e, consequentemente, avanços e incorporações dessa disciplina nos conteúdos programáticos das escolares. Fatos esses que dificultam traçar uma cronologia ou mesmo um entendimento do desenvolvimento teórico, conceitual e didático-pedagógico do ensino da Sociologia na educação escolar.

O ensino da Sociologia e sua inclusão ou exclusão das bases curriculares da educação básica esteve entremeado com as posições e propostas políticas pedagógicas dos diferentes períodos históricos brasileiros, em conexão com os desenvolvimentos dos estudos sociológicos desenvolvidos, inicialmente, na Europa. Segundo Meucci (2000), por exemplo, em meados dos anos 1920 e 1930 buscando a consolidação de um estado laico e que se distanciasse de explicações católicas, manuais de sociologia com teorias positivistas, evolucionistas e cientificistas foram introduzidos pela primeira vez, através da Reforma de João Luis Alves-Rocha Vaz, no sistema educacional brasileiro. Esse foi um dos marcos fundamental para a institucionalização das Ciências Sociais/Sociologia no sistema de ensino.

O fato da Sociologia ser ensinada nas escolas demandou a criação de um mercado de ideias, de circulação de conteúdos que precisava ser ordenado e dinamizado. Isso levou a criação de faculdades e universidades para formar os professores especializados nas novas áreas e também a criação de livros didáticos. Portanto, no Brasil nota-se que foi pela dimensão do ensino da Sociologia na escola que, inicialmente e oficialmente, instalou-se essa disciplina no Brasil. Tal fato é, no entanto, pouco difundido e ensinado nos cursos de Ciências Sociais/Sociologia na atualidade.

No período de 1930 e 1940, autores como Gilberto Freyre no Recife, Fernando de Azevedo em São Paulo, Artur Ramos no Rio de Janeiro, entre outros iniciam uma produção de material para o ensino da Sociologia no Brasil. Materiais esses que depois se desdobraram em teorias e métodos sociológicos na construção da sociologia brasileira. O contexto político brasileiro dos anos de 1930 até 1964 era promissor e cheio de mudanças como, por exemplo, o crescente processo de urbanização, industrialização, capitalismo expansionista, migrações internacionais e mudanças sociais, trabalhistas e culturais. Tais transformações sociais favoreceram a consolidação das Ciências Sociais/Sociologia no ensino superior. No entanto, 
sua obrigatoriedade foi flexibilizada no ensino secundário, ficando obrigatório só para as escolas normais.

No período que se sucede, de 1964 até a redemocratização e posteriormente até 2008, o ensino da Sociologia ficou mais voltado ao ensino superior. Nesse período os cursos de licenciaturas em Ciências Sociais focavam os seus conteúdos pedagógico-didáticos para o ensino da Sociologia em nível de graduação e pós-graduação. Tal fato levou há uma grande cisão entre o ensino da Sociologia para docência e a formação para a pesquisa através do bacharelado. Nesse sentido, pelo país foi possível observar curso em Ciências Sociais que forneciam apenas a formação de bacharel, não havendo disponível na grade curricular licenciatura (Werneck Vianna, et al. 1998). Em tal período, a não obrigatoriedade da Sociologia no ensino básico levou também, segundo Moraes (2003), a intermitência nas reflexões no interior da comunidade das Ciências Sociais, e a uma menor valorização da licenciatura. Resultando em poucas pesquisas com relação ao ensino da Sociologia no Brasil.

Tal fato foi alterado somente com a promulgação da lei n 11.684/2008 (Brasil, 2008), que alterou o entendimento das Diretrizes Curriculares Nacionais para o Ensino Médio (DCNEM) de 1998. Nessas DCNEM, o ensino da Sociologia voltava às bases curriculares do ensino básico no Brasil, no entanto, ficou estabelecido que os conteúdos sociológicos seriam ensinados de forma transversal, através de outras disciplinas. Assim sendo, o ensino da Sociologia como disciplina autônoma não se tornou obrigatória na grade curricular da educação básica. Isso fez com que a disciplina de Sociologia ficasse, em concreto, fora dos currículos escolares. Apenas em 2008, tal entendimento foi alterado e Sociologia passou a ser disciplina obrigatória. A partir de então é possível observar uma crescente (re) estruturação do campo de ensino e de pesquisa em sociologia escolar.

Essa mudança levou a reformulação de cursos de licenciatura pelo país, na publicação de novos livros didáticos, no aquecimento do debate em congressos da área (SBS, por exemplo), no aumento expressivo de dissertações e de teses sobre a temática e no surgimento de revistas (por exemplo: Cadernos da Associação Brasileira de Ensino das Ciências Sociais) e entre outros. Como dito por Fiorelli (2014), inicia-se a formação de um campo de estudo voltado ao ensino da Sociologia.

Com o processo de consolidação do ensino da Sociologia na escola passa a surgir estudos em que os principais debates, segundo Leal e Yung (2015:774), serão entorno: 
1) da institucionalização da disciplina, 2) da legitimação da disciplina no espaço escolar, 3) das atribuições para intelectualizar o alunato e 3) prepará-lo para práticas cívicas e interpretativas assentadas no sentido moderno de reflexividade.

Esses estudos abriram espaço de debate para a construção de uma Sociologia do ensino da sociologia no Brasil. Assim autores, como Leal e Yung (2015) e Leal (2017) demonstraram que as principais diretrizes sobre o ensino da Sociologia nas escolas brasileiras foram pautadas em um modelo escolar nacional em que entende a escola como locus do paradigma democrático-republicano, no sentido liberal, da meritocracia. Nesse sentido, o ensino da Sociologia nas escolas é constantemente definido como sendo, dentro de um modelo "durkheniano", como produtora da coesão social e socialização, cabendo à disciplina o ensinamento das normas sociais que nos permitiriam viver em sociedade.

Portanto, muitas das vezes, a disciplina de Sociologia é descrita e entendida nas diretrizes curriculares, assim como, pelos docentes e alunos, tendo como objetivo central incarnar orientações cívicas e civilizatórias como parte dos seus resultados (ver Leal, 2017). Essa concepção enquadrou a disciplina de Sociologia na escola como uma ponte entre o sujeito/indivíduo e a realidade social na busca de um sujeito crítico que formaria o aluno enquanto cidadão.

Tal concepção tem força de convencimento nos espaços políticos e educacionais para legitimação da disciplina, continuidade e consolidação nas bases curriculares. No entanto, pouco trás sobre a reprodução das desigualdades e distinções no âmbito das escolas e pouco discute o papel da sociologia na construção e desconstrução dessas desigualdades, e, ainda de sobre sua utilidade para debater sobre diversidades.

Autores clássicos como Bourdieu (1964) demonstraram como a escola não cumpre com o papel democrático, republicano, universalizador e civilizatório, mas sim é um espaço social, como outros, construído na sociedade moderna industrial, de (re) produção de desigualdades sociais. Dentro dessa concepção, a escola perderia a sua "aurea" de locus social neutro, que possibilita a mobilidade social dos indivíduos de classes sociais não dominantes. Ela passa a ser um espaço social de (re)produção e perpetuação da cultura dominante. Nesse sentido, qual seria, portanto, o papel da Sociologia para as escolas? Como poderia a Sociologia ser ensinada em tal contexto? Como as metodologias e técnicas sociológicas podem contribuir para o alunato escolar? Ademais, como o ensino da Sociologia pode contribuir para o alunato imigrante, que chegou ao Brasil nesses últimos anos? 


\section{O Ensino da Sociologia e o Alunato Imigrante}

Segundo o autor Lahire (2014), o ensino da Sociologia nas escolas desempenha um papel crucial para a vida coletiva e para a formação de cidadãos nas sociedades democráticas. Não em um sentido de formação cívica, mas como sujeitos agentes e pensantes sobre o mundo social em que habitam. Esse autor argumenta que "filhas da democracia", as ciências sociais, buscam a produção de "verdades" (no plural) sobre o mundo social e infelizmente as verdades das sociedades contemporâneas são as desigualdades, as dominações, as opressões, as explorações, as humilhações. Para esse autor, as Ciências Sociais/Sociologia encontram resistência para se firmarem nos currículos escolares e precisam constantemente buscar elementos para sua legitimação, devido à própria lógica da reprodução escolar. O sistema escolar é entendido como um espaço de neutralidade das ciências e, assim, acreditasse e advogasse que a escola deva ser um espaço neutro de disputas, discursos e ideologias sociais.

Contrariando os currículos escolares de diversos países, para esse autor a Sociologia deveria ser incluída nas bases curriculares desde os primeiros anos escolares. Já que as técnicas de reflexão sociológicas permitiriam aos alunos uma compreensão do mundo social não etnocêntrica. A ideia, segundo a qual ensinar reflexividade sociológica só poderia ocorrer após a formação moral e cultural da criança, já que essa poderia ser uma operação psicologicamente desestabilizadora é uma concepção totalmente fundada na lógica do etnocentrismo. Essa parte do princípio de que é necessário construir suas referencias, suas "marcas", sua "identidade", antes mesmo de poder começar a tomar consciência da diversidade social (cultural, civilizacional, politica, etc.). Essa forma de construção de identidades tem um caráter de exclusão e de "repudiar pura e simplesmente formas culturais: morais, religiosas, sociais, estéticas que são as mais distantes daquelas com as quais nos identificamos" (Lahire, 2014 apud LEVI-STRAUSS, C. Race et histoire. Paris: Folio, 1987, p. 19).

É nesse sentido que o ensino da Sociologia se faz tão relevante para o contexto brasileiro atual e para o alunato imigrante. A Sociologia poderia ser a disciplina de reflexão sobre a diversidade social. O mundo brasileiro atual exige mais "imaginação sociológica" (Mills, 1959) para ser apreendido. A identidade individual e a personalidade da criança e de jovens não deveriam ser construída fora do exercício de reflexão que lhes possibilita as Ciências Sociais, já que o convívio com o diferente, o "outro" se dá cada vez mais. Assim 
sendo, o ensinar sociológico e as maneiras de pensar que as ciências sociais constituíram de maneira eficaz desde o século XIX, com bases científicas e empíricas, poderiam através de mediações pedagógicas serem adaptadas ao espaço escolar.

O modo de se pensar construído pela Sociologia, conceitualmente e também suas metodologias de pesquisas, poderiam ser introduzidas no âmbito do ensino básico como forma de desnaturalizar e historicizar formas e normas sociais consideradas "adequadas" e "fixas". Ao demonstrar que nem sempre foi assim, que a socialização e as identidades culturais são processos diferentes no tempo e espaço, a Sociologia tem um papel para além de cívico, ela abre a possibilidade para transformar e ampliar o poder de agencia nos alunos.

É nesse sentido que a combinação de uma Sociologia do ensino da sociologia e o campo das migrações se faz necessário e urgente. É preciso, entender que o sucesso escolar do alunato imigrante dependerá muito de um conhecimento escolar das singularidades desses alunos e, ainda, de visualizar a sua experiência de forma para além dos parâmetros curriculares nacionais.

Lahire (2014), que estudou imigrantes no sistema escolar Francês, observa que medir o sucesso escolar desses grupos, que geralmente são desprovidos de capital econômico e mesmo cultural e social com relação aos nacionais, tem que ir além das configurações nacionais. O sucesso educacional do alunato imigrante terá, por exemplo, que ter como referencia à construção de família transnacional e a transposição de conhecimentos culturais e sociais através desse formato de família ${ }^{2}$. Também será necessária a adequação curricular, entendimento de outros sistemas educacionais, relativização dos currículos e descolonização do pensamento, que valoriza alguns diplomas em detrimentos de outros. Enfim, a Sociologia tem muito a contribuir para a formação de um ensino básico brasileiro, que seja inclusivo dentro da gama de diversidade que a cada dia somos apresentados.

\section{Considerações Finais}

O presente texto teve como intuito chamar atenção para a necessidade de avançar em estudos que inter-relacione o ensino da Sociologia e o alunato imigrante nas escolas. A pergunta: qual a utilidade do ensino de Sociologia para a educação básica no Brasil? É extremamente atual e insofismável. Nos dias atuais diversos discursos (re) surgiram como o

\footnotetext{
${ }^{2}$ Sobre a construção de famílias transnacionais ver Tonhati, T. (2017).
}

Revista de Estudos e Pesquisas sobre as Américas V.13 N.1 2019 ISSN: 1984-1639 
debate entre socialismo/comunismo versus liberalismo e, ainda, sobre feminismo, desigualdades, preconceitos, migrantes “ilegais", construção de muros, legalização ou não de armas, violência, terrorismo, ataques armados, democracia versus ditaduras, direitos civis, políticos, cidadania, movimentos sociais. A Sociologia é por excelência o campo desses debates, de suas conceptualizações e sistematizações de forma científica, através de pesquisas empíricas com metodologias adequadas.

Através do estudo dos conteúdos sociológicos, que muitas das vezes são flexíveis e adaptáveis às realidades vividas, é possível a "desnaturalização" e a construção de "estranhamentos". Os métodos de observação dessa disciplina pode permitir as crianças e jovens da educação básicas brasileiras (migrantes e não-migrantes) ampliar sua gama de interpretações sobre o seu cotidiano. Ademais, a Sociologia pode possibilitar a esses entenderem como os fenômenos políticos, econômicos, culturais e até mesmo decisões familiares e individuais são frutos de um amplo processo histórico e social.

Apesar dos avanços e diversas possibilidades que essa disciplina traz para a educação básica, é preciso conhecer o campo de luta do ensino da Sociologia e assim saber que essa está mais uma vez ameaçada. Como demonstrado anteriormente, o ensino de Sociologia tem sido intermitente no Brasil, com período de estabilidade e florescimento e momento de retrocessos e estagnação. Processos esses ligados aos momentos políticos no país. Atualmente, o ensino de Sociologia nas escolas passa mais uma vez por um momento de incerteza. A nova Lei de reforma do ensino médio (13.415/2017) prevê apenas a obrigatoriedade de "estudos e práticas de Educação Física, Artes, Sociologia e Filosofia”, não determina a obrigatoriedade das disciplinas. Tal fato pode retroceder o ensino da Sociologia na educação básica ao que existia antes de 2008. O conteúdo de Sociologia era entregue a profissionais não formados na área sendo considerado um conteúdo transversal.

Nesse contexto, todos os avanços conquistados em torno das práticas de ensino, a construção de um repertório significativo de experiências, pesquisas, livros didáticos, que possibilitam a (re) contextualização dos conteúdos para os alunos da educação básica, podem sofrer uma interrupção. Tal fato, também, afetará profundamente os cursos de licenciaturas em Ciências Sociais/Sociologia, uma vez que os graduados terão limitados espaços de atuação profissional.

Enfim, é preciso entender que o campo de luta do ensino da Sociologia continua e a expansão da disciplina nos últimos anos não significou sua consolidação definitiva nas bases 
curriculares. Aos sociólogos no ensino superior ou básico é preciso estar atentos às reformas educacionais, mudanças curriculares e alterações na conjuntura política do país. E, também, é necessário constantemente (re) estruturar e (re) pensar as áreas de metodologia, estágios, formação e pesquisas nos departamentos de Ciências Sociais para garantir a continuidade da disciplina e sua conexão com as novas realidades políticas e sociais nacionais e transnacionais.

\section{Referências}

BOURDIEU, P; PASSERON, J. Os Herdeiros: os estudantes e a cultura. Florianópolis: Editora da UFSC, 2014.

CAVALCANTI, L; TONHATI, T.; DUTRA, D.; OLIVEIRA, M (Org.). A imigração haitiana no Brasil: características sócio-demográficas e laborais na região sul e no Distrito Federal. 1. ed. Santiago: Universidad de Desarrollo (UDD), 2016. v. 1. p.149.

FIORELLI, I. L. (2010) Capítulo 1. O ensino das Ciências Sociais/Sociologia no Brasil: histórico e perspectivas. In: Sociologia: ensino médio / Coordenação Amaury César Moraes. Brasília: Ministério da Educação, Secretaria de Educação Básica, 2010, p. 15-45. (Coleção Explorando o Ensino; v. 15)

FIORELLI, I. L. (2014), A sociologia de volta à escola: um balanço provisório. Revista de Ciências Sociais, Fortaleza, v. 45, n. 1, 2014, p. 277-284.

HANDERSON, J. Diáspora. As dinâmicas da mobilidade haitiana no Brasil, no Suriname e na Guiana Francesa. Tese de doutorado. Rio de Janeiro: UFRJ/Museu Nacional, 2015.

LAHIRE, B. Viver e interpretar o mundo social: para que serve o ensino da Sociologia? Revista de Ciências Sociais, Fortaleza, v. 45, n. 1, jan/jun, 2014, p. 45-61

LAI AMÂNDIO, S. O fio constitutivo da sociologia empírica de Bernard Lahire, Sociologia, Problemas e Práticas [Online], 76 | 2014, posto online no dia 04 novembro 2014, consultado no dia 04 abril 2019. URL : http://journals.openedition.org/spp/1669

LEAL, S. (2017). Dispositivos de normatização do ensino de sociologia na escola: formação e saberes docentes de licenciandos em ciências sociais no distrito federal Educ. Soc., Campinas, v. 38, no. 141, p.1075-1099, out.-dez., 2017.

LEAL, S. e YUNG, T. Por uma sociologia do ensino de sociologia nas escolas: da finalidade atribuída à disciplina à experiência social do alunato. Estudos de caso no Distrito Federal. Revista Sociedade e Estado - Volume 30 Número 3 Setembro/Dezembro 2015, p. 773-796. 
MEUCCI, S. A institucionalização da sociologia no Brasil: os primeiros manuais e cursos [1900-1948]. 2000. Dissertação (Mestrado em Sociologia) - IFCHUnicamp,

MILLS, C. Wright. The Sociological Imagination (Oxford: Oxford University Press, 1959)

MORAES, A. C. Licenciatura em Ciências Sociais e Sociologia. Tempo Social, São Paulo, v. 15, n. 1, p. 5-20, maio 2003.

OLIVEIRA, T. (2018). Movimentação e registro de migrantes no Brasil: dados do STI e SINCRE. In: Cavalcanti, L; Oliveira, T.; Macedo, M., Migrações e Mercado de Trabalho no Brasil. Relatório Anual 2018. Série Migrações. Observatório das Migrações Internacionais; Ministério do Trabalho/ Conselho Nacional de Imigração e Coordenação Geral de Imigração. Brasília, DF: OBMigra, 2018, p. 55-75.

SILVA, S. Fronteira amazônica: passagem obrigatória para haitianos? REMHU - Rev. Interdiscip. Mobil. Hum., Brasília, Ano XXIII, n. 44, p. 119-134, jan./jun. 2015.

SIMÕES, G. Perfil sociodemográfico e laboral da imigração venezuelana no Brasil (Org). Curitiba: CRV, 2017.

TONHATI, T.; CAVALCANTI, L. ; OLIVEIRA, A. T. . Os Imigrantes Haitianos no Brasil: Formas de Entrada, Permanência e Registros. In: CAVALCANTI, L; TONHATI, T.; DUTRA, D.; OLIVEIRA, M (Org.). A imigração haitiana no Brasil: características sóciodemográficas e laborais na região sul e no Distrito Federal. 1ed.Santiago: OIM/Universidad de Desarrollo (UDD), 2016, v. 1, p. 24-40.

TONHATI, T. The transnational family: migration, family and rituals among Brazilian migrant women in the UK. Tese de doutorado. Goldsmiths, University of London, 2017, p. 314.

WERNECK VIANNA, et al. As Ciências Sociais no Brasil: a formação de um sistema nacional de ensino e pesquisa. BIB: Boletim Informativo e Bibliográfico de Ciências Sociais, Rio de Janeiro, n. 40, p. 27-63, 1995.

- Education and Immigration: The Importance of Teaching Sociology to Immigrants

- Educación e Inmigración: la importancia de la enseñanza de la sociología para los inmigrantes 


\title{
Educação e Imigração: a importância do ensino da Sociologia para imigrantes
}

\begin{abstract}
Resumo
O presente artigo, com caráter de ensaio, aborda de forma reflexiva, a relação entre imigração educação. Em concreto o texto tem como objetivo suscitar a necessidade de refletir sobre a importância do ensino da sociologia nas escolas com alunos imigrantes. O número de imigrantes no país vem crescendo nas duas últimas décadas e, consequentemente, também aumentou a entrada de crianças e adolescentes imigrantes no sistema educacional básico do país. Portanto, faz-se necessário pensar como a Sociologia com seus instrumentos conceituais, pedagógicos e metodológicos pode ser um locus para os alunos imigrantes e não-migrantes entenderem melhor as particularidades dos processos migratórios, suas motivações e consequências. Ademais, é relevante pensar como a disciplina de Sociologia pode contribuir para a integração sociocultural e para a socialização dos alunos imigrantes no seu novo contexto cultural. E, ainda, como essa pode colaborar para a escola valorizar as diferenças e particularidades culturais do alunato imigrante.
\end{abstract}

Palavra-chaves: Migração internacional, ensino da Sociologia, crianças e adolescentes.

\section{Education and Immigration: the importance of the teaching of Sociology for immigrants}

\begin{abstract}
This paper approaches in a reflective way the relationship between migration and education. It aims to make a call for more studies on the importance of teaching sociology in schools with immigrant students. The number of immigrants in Brazil has increased in the last two decades. Consequently, it has also increased the number of immigrant children and adolescents into the basic educational system. Therefore, it is necessary to think how sociology with its conceptual, pedagogical and methodological instruments can be a locus for the immigrant and non-migrant students to understand better the particularities of migratory processes, their motivations and consequences. In addition, it is important to think about how the discipline of sociology can contribute to the processes of socio-cultural integration and socialization of immigrant students in their new cultural context. In addition, it is necessary to understand further about how sociology can collaborate for the schools to value the differences and cultural peculiarities of the immigrants.
\end{abstract}

Keywords: International Migration, sociology teaching, children students

\section{Educación e Inmigración: la importancia de la enseñanza de la sociología para los inmigrantes}

\section{Resumen}

El presente artículo, con carácter de ensayo, aborda de forma reflexiva, la relación entre inmigración educación. En concreto, el texto tiene como objetivo suscitar la necesidad de reflexionar sobre la importancia de la enseñanza de la sociología en las escuelas con alumnos inmigrantes. El número de inmigrantes en el país ha crecido en las dos últimas décadas y, consecuentemente, también ha aumentado la entrada de niños y adolescentes inmigrantes en el sistema educativo básico del país. Por lo tanto, se hace necesario pensar cómo la sociología con sus instrumentos conceptuales, pedagógicos y metodológicos puede ser un locus para que los alumnos inmigrantes y no migrantes entiendan mejor las particularidades de los procesos migratorios, sus motivaciones y consecuencias. Además, es relevante pensar cómo la disciplina de Sociología puede contribuir para la integración sociocultural y la socialización de los alumnos inmigrantes en su nuevo contexto cultural. Y, además, como esta puede colaborar para la escuela valorar las diferencias y particularidades culturales de los estudiantes inmigrantes.

Palabra clave: Migración internacional, enseñanza de la sociología, niños y adolescentes.

Revista de Estudos e Pesquisas sobre as Américas V.13 N.1 2019 ISSN: 1984-1639 